\title{
A juventude pensada a partir do envelhecimento: demografia e comportamento político dos grupos geracionais
}

\author{
Simone Pereira da Costa Dourado \\ Doutora em Ciências Sociais (Universidade do Estado do Rio de Janeiro) \\ Professora da Universidade Estadual de Maringá, Maringá \\ Paraná, Brasil \\ simone@wnet.com.br \\ Carla Almeida \\ Doutora em Ciências Sociais (Universidade Estadual de Campinas) \\ Professora da Universidade Estadual de Maringá, Maringá \\ Paraná, Brasil \\ carlaalm@uol.com.br
}

\begin{abstract}
Resumo A participação política pensada a partir de recortes geracionais tem atribuído às ciências sociais novas e inquietantes questões. Neste artigo se analisa o comportamento político dos jovens e dos idosos residentes na cidade de Maringá, norte do Paraná, com base em dados fornecidos por um survey aplicado para uma amostra da população da cidade ao longo do ano de 2011. O artigo está organizado em três partes: na primeira se discute como juventude e velhice são categorias socialmente construídas, sendo que, na atualidade, os jovens são considerados em função do vertiginoso crescimento demográfico dos idosos; na segunda, dá-se dimensão à presença dos jovens e dos idosos em Maringá, e na terceira, discute-se o comportamento político dos jovens e dos idosos nesse município.
\end{abstract}

Palavras-chave: juventude, envelhecimento, comportamento político, demografia de grupos geracionais.

\section{Introdução}

participação política, pensada a partir de recortes geracionais, tem
colocado às ciências sociais novas e inquietantes questões. Algumas
fortes representações criadas pelo senso comum destinam aos jovens e
aos velhos, grupos que ocupam os extremos do ciclo da vida, ora posi-
ções semelhantes, ora posições diametralmente opostas. Assim, muitas
vezes jovens e idosos são classificados como os grupos que menos parti-
cipam do mundo da política, em suas diversas dimensões: partidos po-
líticos, movimentos sociais, contestatórios e reivindicatórios, processos
eleitorais etc. Uma confirmação dessa postura distanciada de jovens e
idosos das formas de participação política poderia, segundo essas clas-
sificações, ser confirmada com o reconhecimento tardio desses grupos
geracionais como sujeitos de direitos específicos, pois, no Brasil, os es-
tatutos do Idoso e da Juventude tiveram aprovação em outubro de 2003
e agosto de 2013, respectivamente. Em outros momentos, a juventude
é classificada como um grupo que naturalmente tende à contestação,
sendo ela vinculada às atitudes progressistas no universo da participação 
política, enquanto, em contraposição, aos idosos são tributadas atitudes conservadoras e a omissão.

Note-se a diferença de uma década entre a promulgação do Estatuto do Idoso, voltado para o atendimento daqueles que têm 60 ou mais anos de idade, e o Estatuto da Juventude. Apenas no ano de 2013 o Estado brasileiro reconheceu a necessidade de criar uma lei que dispõe sobre os direitos dos jovens e define os princípios e as diretrizes para as políticas públicas de juventude, avaliando que o grupo de pessoas que estão na faixa etária de 15 a 29 anos não são contemplados pelo Estatuto da Criança e do Adolescente (Lei n. 8.069, de julho de 1990) e precisam de um instrumento legal que assegure os seus direitos.

Em outros contextos explicativos do comportamento político, jovens e idosos também podem ser classificados como grupos que apresentam posições opostas (Simões, 2006; Stucchi, 2006). É comum ser tributado à juventude um espírito participativo, contestatório e até revolucionário, enquanto aos idosos são atribuídas posturas conservadoras, a abstenção do debate político e da participação, inclusive em razão da não obrigatoriedade do voto a partir dos 70 anos. No Brasil, o voto é obrigatório para os indivíduos maiores de 18 anos e facultativo para analfabetos, maiores de 70 anos e maiores de 16 anos e menores de 18 anos.

Nas teorias que associam a participação política aos ciclos de vida, há vertentes, conforme aponta Okado (2013), que defendem a ideia de que haveria uma lógica curvilínea no decorrer da vida, na qual a participação se iniciaria baixa na juventude, atingiria o ápice na vida adulta e começaria a declinar na velhice. Para Milbrath e Goel (1977), por exemplo, aquela curva deve-se aos diferentes momentos de socialização vividos pelos indivíduos nas diferentes etapas de sua vida. Casamento, entrada no mercado do trabalho e aposentadoria alterariam as redes de relacionamento dos indivíduos, impactando suas inserções no mundo da política.

As análises de Karl Mannheim (1961), particularmente aquelas apresentadas em seu ensaio "O problema da juventude na sociedade moderna", publicado na obra Diagnóstico de nosso tempo, são particularmente importantes para a compreensão das relações entre juventude e envelhecimento, no que se refere às formas de participação política adotadas por esses dois grupos. Afinal, o problema instituído por Mannheim (1961, p. 36) - segundo a formulação "O que a juventude nos pode dar?" - continua sendo uma boa questão para pensar as relações entre jovens e idosos em sociedades como a brasileira, que vivem significativas modificações em sua estrutura demográfica.

Neste artigo, analisamos o comportamento político dos jovens edos idosos residentes na cidade de Maringá, norte do Paraná, a partir de dados fornecidos por um survey aplicado para uma amostra da população da cidade ao longo do ano de $2011 .{ }^{1}$ Nosso objetivo é discutir se as visões de mundo que tributam à juventude e à velhice apatia política e baixa participação se confirmam. E, ainda, se a perspectiva que contrapõe jovens como revolucionários, ativos e participativos e idosos como desmotivados e distantes das formas de participação política pode ser projetada para o caso que focalizamos.

Este artigo está organizado em três partes: na primeira, discutimos como juventude e velhice são categorias socialmente construídas, pois, na atualidade, os jovens são pensados em função do vertiginoso crescimento demográfico dos idosos; na segunda, dimensionamos a presença dos jovens e dos idosos em Maringá, e na terceira, apresentamos e discutimos o comportamento político dos jovens e dos idosos em Maringá.

\section{Juventude: categoria social pensada a partir da velhice}

Jovens e idosos são categorias sociais construídas a partir de algumas arbitrariedades, como a que fixa uma faixa etária específica para cada grupo (Bourdieu, 1983, p. 112). No Brasil, quando a referência são os marcos regulatórios fornecidos pelos estatutos da Juventude e do Idoso, as definições são as seguintes: jovens são aqueles que têm entre 15 e 29 anos, e idosos, os que possuem 60 ou mais anos de idade. Bourdieu (1983, p. 112) ensina que a fronteira entre a juventude e a velhice é razão de disputa em todas as sociedades e, portanto, definir que alguém é jovem ou idoso significa impor limites e criar ordens, como aquelas que regulam os processos políticos e eleitorais. No Brasil, o jovem que completa 16 anos

\footnotetext{
1. Trata-se de dados coletados no âmbito de um projeto de pesquisa mais amplo, denominado "Cultura, Política, Gênero e Eleições", que contou com o apoio do CNPq. Esse projeto teve como objetivo investigar os determinantes individuais e subjetivos que sustentam o fenômeno da reduzida presença feminina na política. O cálculo da amostra probabilística foi realizado levando em consideração dados do IBGE sobre a população do município de Maringá maior de 16 anos (284.602), um intervalo de confiança (erro amostral) de 5,5\% e nível de confiança de 95\%. Foram conduzidas 309 entrevistas. Para garantir a representatividade da pesquisa, foi empregada a técnica de amostragem de etapas múltiplas. Em primeiro lugar, foram listados os setores domiciliares de Maringá, segundo a última base da malha censitária do IBGE. Esses setores foram atualizados para delimitar o número efetivo de domicílios. Uma vez atualizados os setores, foram sorteadas as unidades domiciliares. Na terceira etapa foi aplicado um sistema de cotas, de modo a garantir uma composição amostral semelhante à encontrada na população em termos de atributos fundamentais (sexo, idade e escolaridade). Agradecemos a Eder Gimenez pelo auxílio com as tabelas.
} 
de idade pode votar se quiser, pois, para ele, o voto é facultativo. O jovem que tem 18 anos é obrigado a votar. Em relação aos idosos, eles devem votar até completar 70 anos de idade, depois ficam em condição semelhante à dos jovens que são maiores de 16 e menores de 18 anos: votam se quiserem. Assim, a legislação eleitoral impõe limites e cria ordens precisas para esses diferentes grupos geracionais e, ao fazer isso, institui proximidades socialmente imprevistas: coloca em um mesmo grupo os que possuem o direito ao voto facultativo (jovens maiores de 16 e menores de 18 anos e idosos com mais de 70 anos) e, em outro grupo, os que são obrigados a votar, os jovens que chegaram aos 18 e os idosos que acabaram de entrar na velhice.

Jovens e idosos compartilham uma posição marginal nas sociedades modernas. Mannheim (1961, p. 42) afirma que, "na linguagem da Sociologia, ser jovem significa sobretudo ser um homem marginal, em muitos aspectos um estranho ao grupo". Estudos sobre o processo de envelhecimento indicam a mesma condição para os mais velhos (Beauvoir, 1990; Bosi, 2010). A velhice pode ser percebida de muitas formas, mesmo porque, como mostra Beauvoir (1990), não é adequado falar em velhice, no singular, e sim em velhices, no plural. Ao distinguir o processo de envelhecimento do momento da chegada à velhice, fase em que o risco de ficar doente e de perder as capacidades funcionais (físicas e mentais) aumenta, a autora indica que há algo que corresponde às mudanças orgânicas, que acompanha o desenvolvimento do corpo biológico, e algo que está relacionado com a definição pessoal, um momento específico em que cada indivíduo constata que ficou velho.

Portanto, para além das definições fornecidas por organismos nacionais e internacionais de controle e contagem populacional e das instituições estatais que delimitam os grupos geracionais, visando o planejamento de políticas públicas específicas, os indivíduos que integram os mais diferentes grupos nas sociedades constroem a suas próprias percepções da juventude e da velhice. Vale frisar que, dependendo do recorte escolhido para analisar juventude e envelhecimento, o étnico, o de gênero, o de classe social, o de escolarização etc., o mais correto é partir do pressuposto de que se está sempre diante de muitas juventudes e de múltiplos processos de envelhecimento.

O rápido processo de envelhecimento da sociedade mundial tem instituído, ao nosso ver, uma nova forma de refletir sobre os grupos geracionais, particularmente no que tange os mecanismos que separam jovens de idosos. A juventude, antes pensada por si, como "parte importante das reservas latentes que se acham presentes em toda sociedade" (Mannheim,
1961, p. 42), passa a ser observada pela sua condição inevitável e, cada vez mais frequente, de chegada em outra fase da vida, à velhice. Assim, o envelhecimento nas sociedades complexas, moderno-contemporâneas é, também, um fenômeno que pode trazer "a flexibilização das classificações das idades, o esmaecimento das fronteiras etárias, a pluralidade e a heterogeneidade de experiências geracionais" (Barros, 2011, p. 47). Nessas sociedades, o modelo sequencial das idades etárias é desestabilizado, particularmente quando confrontado com categorias sociais que nos distinguem historicamente, tais como classe, gênero e etnia.

Dessa forma, porque não podemos falar de uma única juventude nem de um mesmo processo de envelhecimento, é que apresentamos uma reflexão sobre o comportamento político desses diferentes grupos geracionais na cidade de Maringá, localizada na região sul do país, no norte do estado do Paraná, com uma população de 385.753 habitantes. Consideramos relevante entender a participação política a partir da significação que ela tem para determinadas populações, inseridas em determinados contextos. ${ }^{2}$ Assim, uma análise das relações que jovens e idosos estabelecem com o mundo da política, em uma cidade de médio porte da região sul do Brasil, possibilita-nos compreender o interesse que esses diferentes grupos nutrem em relação ao mundo da política e da participação popular.

\section{Dimensionando jovens e idosos em Maringá}

A redução da taxa de fecundidade e o aumento da longevidade humana caracterizam o fenômeno universal da transição demográfica. Esse fenômeno indica que a dinâmica do crescimento populacional é típica do século XX (Brito, 2008). Todos os países passaram, estão passando ou vão passar pela transição de um regime de alta fertilidade, associado à mortalidade elevada, para um padrão de baixa fertilidade, com a diminuição da mortalidade e o aumento da longevidade (Vasconcelos; Gomes, 2012). A rotina ocorre da seguinte forma: primeiro ocorre a redução da mortalidade e, depois, a queda da natalidade. Contudo, os países vivem o fenômeno da transição demográfica de forma diferenciada, como pontua Brito (2008, p. 7):

A transição demográfica nos países em desenvolvimento, latino-americanos e asiáticos, tem sido muito mais acelerada do que naqueles desenvolvidos. No 
caso do Brasil, o declínio da fecundidade, após 1965, teve impacto, lógico, na redução do crescimento da população.

A peculiaridade da transição demográfica brasileira reside no fato de ela ser determinada por desequilíbrios regionais e sociais. Assim, em algumas regiões do país ela pode potencializar o crescimento da economia e do bem-estar social da população e em outras, ampliar graves desigualdades sociais.

No Brasil, a Taxa de Fecundidade Total (TFT), que é uma estimativa do número médio de filhos, nascidos vivos, que uma mulher teria até o fim de seu período reprodutivo (Vasconcelos; Gomes, 2012, p. 541), reduziu muito quando se observa a sequência de séries históricas fornecidas pelos censos populacionais do IBGE. Entretanto, a TFT tem uma distribuição regional muito diferenciada: em 1970, na região Norte do país, ela era de 8,15 filhos por mulher; em 1980, de 6,40; em 1991, de 3,99; em 2000, de 3,16 e em 2010, de 2,47. Considerando essa mesma série, na região Sul, visualiza-se o seguinte quadro de redução do número de filhos por mulher: em 1970, 5,42; em 1980, 3,60; em 1991, 2,45; em 2000, 2,24 e em 2010, 1,78. Logo, considerando apenas o cenário recente, na última década, a região Norte tem um quadro em que a sua potencialidade de crescimento populacional ainda é maior do que a do Brasil, que atinge em 2010 uma TFT de 1,90 filhos por mulher. Por sua vez, a região Sul do país, que tem uma TFT de 1,78 filhos por mulher, está abaixo da linha de reposição da população, que é de 2,1 filhos por mulher.

Ao comparar a Taxa de Fecundidade Total com o Índice de Envelhecimento (IE), que é composto pelo número de pessoas de 60 ou mais anos de idade, para cada cem pessoas menores de 15 anos, torna-se possível visualizar com mais clareza os diferentes graus da transição demográfica brasileira. Em 1970, na região Norte do país, o IE é de 8,2\%; em 1980, de 8,9\%; em 1991, de 10,7\%; em 2000, de $14,6 \%$ e em 2010 , de $24,6 \%$. Na região Sul, considerando a mesma série histórica, a relação de idosos com 60 ou mais anos para cada grupo de 100 pessoas menores de 15 anos é a seguinte: em 1970, 11,1\%; em 1980, 16,6\%; em 1991, 24,0\%; em 2000, 33,5\% e em 2010, 55,0\%. Ou seja, em 2010, o IE da região Sul é mais do que o dobro registrado na região Norte.

O IE tem também um impacto no percentual de idosos com 60 ou mais anos na população global das regiões brasileiras. Nas décadas de 1970 e de 1980, na região Norte, os idosos eram $4 \%$ da população total da região; em 1991, 5\%, percentual que é mantido em 2000, e somente em 2010 passou para 8\%. Na região Sul, em 1970, eles eram 5\% da população; em 1980, 6\%; em 1991, 8\%; em 2000, 9\%; e em 2010, $12 \%$. O peso dos idosos na população total dessas duas dife- rentes regiões brasileiras indica a agudeza das diferenças regionais: na região Norte, em quatro décadas, a população com 60 ou mais anos de idade cresceu apenas um ponto percentual, saindo, em 1970, do patamar de $4 \%$ da população total para 5\% em 2000. Nessas mesmas quatro décadas, a participação da população idosa na região Sul do país evoluiu em quatro pontos percentuais, indo de $5 \%$, para $9 \%$.

Essas informações mostram o nível das desigualdades regionais e confirmam que a transição demográfica será vivida de forma muito diferenciada pelas regiões Norte e Sul. Estas irão experimentar, em séries históricas muito distintas, a abertura das janelas de oportunidades demográficas gerada no momento em que os jovens (menores de 15 anos) e os idosos (60 ou mais anos de idade) possuírem um peso pequeno nas suas populações. Como destaca Brito (2008, p. 17): "O aumento do tamanho absoluto e do peso relativo da população em idade ativa, em relação aos dependentes, jovens e idosos, do ponto de vista estritamente demográfico, pode ser considerado um fator positivo para economia".

Ao considerar o quadro comparativo entre as regiões Norte e Sul do Brasil, percebe-se que a janela de oportunidades demográficas da segunda foi potencialmente aberta em 2010 e deve permanecer assim até 2030. A região Norte deve abrir sua janela mais tarde, aproximadamente na década de 2020. Contudo, é preciso considerar que o aproveitamento do bônus demográfico para as duas regiões, ou para qualquer outra região brasileira, está condicionado à implantação de políticas públicas que efetivem os benefícios demográficos. É preciso considerar, por exemplo, que o pressuposto de que os jovens e os idosos consomem mais do que produzem e que a população economicamente ativa produz mais do que consome pode ser abalado pela seguinte situação da transição demográfica brasileira: por um lado, as ocupações precárias, com alto grau de informalidade no emprego e pagamento de baixos salários à população economicamente ativa; por outro lado, os maiores índices de crescimento demográficos estão entre os que integram a parcela da população mais pobre. Assim, como pontua Brito (2008, p. 18-20):

Os demógrafos têm chamado atenção para as oportunidades demográficas que poderiam ser usufruídas pela sociedade e economia, entre 2010 e 2030, em função, principalmente, do crescimento da PIA, acompanhado pela redução de dependência total, que, nesse período, alcançará seus menores valores, em torno de $50 \%$, sendo que o peso relativo dos idosos ainda será bem menor do que o dos jovens. Ter-se-ia, para cada 100 pessoas em idade ativa, apenas 50 jovens e idosos, com preponderância dos jovens. [...] Entretanto, quando considerada a realidade da 
sociedade brasileira, em que o número de pessoas desocupadas é ainda muito grande, a razão de dependência demográfica pode não ser um indicador suficiente.

É importante destacar que o bônus demográfico só será aproveitado integralmente se as desigualdades sociais forem reduzidas. Por isso, os analistas apontam para a necessidade de políticas públicas que pensem de forma articulada os diferentes grupos geracionais e ocupacionais e as diferentes regiões do país.

A cidade de Maringá, no estado de São Paulo, segue comportamento semelhante ao da região Sul do Brasil no que se refere à redução da Taxa de Fecundidade Total (TFP) e ao processo de envelhecimento. Em 1991, Maringá tinha uma taxa de TFT de 2,24 filhos; em 2000 caiu para 2,11 e em 2010, para 1,40. Em relação à participação da população com 60 ou mais anos de idade no conjunto da população total do município de Maringá, em 2010 ela era de 12,2\%; índice que quase dobrou desde 1991, quando 6,9\% dos maringaenses tinham 60 ou mais anos de idade.

A participação da população jovem, aquela que está na faixa etária de 15 a 29 anos, é como usualmente ocorre nas sociedades contemporâneas que passam pelo processo de transição demográfica, muito mais expressiva. Ela ainda está aumentando, contudo, em um ritmo muito menor do que o do crescimento da população idosa. Em 1991, os jovens de Maringá na faixa etária de 15 a 29 anos constituíam 26,45\% da população total do município; em 2000, eles chegaram aos 27,10\%; e em 2010 eram 27,23\%.

Esse quadro demográfico da sociedade maringaense indica que seu acelerado processo de envelhecimento reproduz uma dinâmica mundial e nacional. A redução significativa do número de filhos por mulheres em idade reprodutiva nessa sociedade indica que, muito antes do que a região Norte do Brasil e mesmo um pouco antes do que a região Sul, a cidade experimentará uma situação em que o número de idosos vai superar o de jovens. Os efeitos dessa inversão para reflexões no terreno da participação política são imprevistos, mas a análise que se segue procura criar uma radiografia para o contexto atual, quando, em termos populacionais, o número de jovens, apesar de crescer em ritmo muito menos acelerado do que o de idosos, ainda é numericamente mais expressivo que o desses últimos.

\section{Comportamento político de jovens e idosos em Maringá}

Mannheim (1961, p. 41) afirma que "a juventude não é progressista nem conservadora por índole, po- rém é uma potencialidade pronta para qualquer nova oportunidade". Os dados de nossa pesquisa confirmam, em certa medida, essa suposição do autor. Mas em relação ao grupo geracional dos idosos, o mesmo poderia ser dito? As informações de nosso survey indicam que não. Se jovens e idosos apresentam posturas muito próximas em relação a discussões mais gerais sobre a participação no mundo da política, no momento em que o nível da participação é mais detalhado, a resposta dos idosos mostra algumas diferenças com a dos jovens, revelando posturas mais conservadoras em relação ao seu envolvimento com o mundo da política e às formas de participação.

As definições etárias que caracterizam os grupos geracionais são sempre arbitrárias, como dissemos anteriormente, incorporando as observações de Bourdieu (1983) sobre o assunto, por não considerarem as percepções de juventude e de velhice construídas pelos diferentes grupos sociais. Mas como construções históricas e sociais, elas têm efetividade na definição das políticas que garantem os direitos desses grupos. Em nossa pesquisa também tivemos de operar com cortes etários que são arbitrários, mas que podem nos ajudar a pensar as semelhanças e as diferenças entre esses diferentes grupos no que se refere à participação política. Para efeito de nossas análises, são considerados jovens os que estão entre 16 e 29 anos e idosos, os que têm 60 ou mais anos de idade. Para os dois grupos, buscamos seguir os recortes etários estabelecidos pelos estatutos da Juventude e do Idoso. Apenas no caso da juventude, o corte etário inicial foi de 16 anos, e não 15 anos, como define o Estatuto da Juventude, porque nos interessa o jovem que pode votar, uma vez que o survey teve a preocupação de aferir a participação política dos eleitores nas eleições presidenciais de 2010.

Para uma apresentação do perfil participativo mais geral do universo investigado, sem a consideração dos grupos etários, a Tabela 1 deixa evidente o alto engajamento dessa população em associativismo de tipo religioso. Essa dimensão associativa, que vincula amplamente os diferentes grupos geracionais às denominações religiosas, unifica, como veremos na Tabela 2, jovens e idosos, confirmando que, nesse âmbito, os dois grupos compartilham duas percepções: 1) integrar um grupo religioso é reconhecido como uma modalidade de participação associativista; 2) o vínculo religioso é a modalidade de participação que recebe atenção prioritária. Recuperando as perguntas de Mannheim (1961, p. 36), podemos afirmar que, nesse particular, jovens e idosos nos fornecem a mesma postura: a religião é um expressivo prisma para se inserir e ler a realidade social.

É importante mencionar que os dados da Tabela 1 resultam da soma, para cada tipo de associativismo considerado, das opções escolhidas pelos res- 
pondentes para as alternativas: "Pertence, mas não participa" e "Pertence e participa". Com esse procedimento, temos um panorama mais amplo do volume dos vínculos associativos presentes nessa população, independentemente do grau de ativismo em que se encontravam os indivíduos no momento em que responderam ao survey.

Tabela 1 - Frequência de vínculos associativos em Maringá

\begin{tabular}{|l|c|}
\hline Modalidade de associativismo & Totais \% \\
\hline Religioso & 82,8 \\
\hline Esportivo/recreativo & 24,3 \\
\hline Filantrópico & 19,1 \\
\hline Cultural/educacional & 16,2 \\
\hline Sindical & 14,6 \\
\hline Comunitário & 13,0 \\
\hline Assoc. profissional & 9,4 \\
\hline Defesa do meio ambiente & 4,2 \\
\hline Partido político & 4,2 \\
\hline Org. mulheres & 2,9 \\
\hline LGBT & 1,2 \\
\hline
\end{tabular}

$\mathrm{N}=309$

Fonte: Projeto Cultura, Política e Gênero.

Tabela 2 - Vínculos associativos por grupos etários

\begin{tabular}{|l|r|r|r|}
\hline $\begin{array}{l}\text { Modalidade de } \\
\text { associativismo }\end{array}$ & \multicolumn{3}{|c|}{ Grupos Etários \% } \\
\hline Religioso & $16-29$ & $30-59$ & $60+$ \\
\hline Esportivo/recreativo & 76,3 & 86,8 & 85,7 \\
\hline Filantrópico & 32,4 & 20,5 & 14,3 \\
\hline Cultura/educacional & 20,2 & 16,9 & 25,7 \\
\hline Comunitário & 18,5 & 15,0 & 14,3 \\
\hline Sindical & 6,1 & 16,3 & 20 \\
\hline Associação profissional & 12,3 & 18,8 & 2,9 \\
\hline Defesa do meio ambiente & 7,0 & 12,6 & 2,9 \\
\hline Partido político & 1,4 & 3,2 & 8,6 \\
\hline Organização de mulheres & 3,5 & 7,9 & 0,0 \\
\hline LGBT & 3,6 & 0,0 & 0,0 \\
\hline
\end{tabular}

$\mathrm{N}=309$

Fonte: Projeto Cultura, Política e Gênero.

Importante mencionar que, caso considerássemos apenas as respostas dadas para a opção "Pertence e participa", a frequência baixaria para todas as modalidades e poderíamos considerar que essa população tem um baixo índice de associativismo. Vale mencionar que apenas para sindicatos e partidos políticos, organizações que estão entre as mais tradicionais da nossa relação, as frequências encontradas para a alter- nativa "Pertence, mas não participa" foram maiores do que as encontradas para "Pertence e participa". Entre as tradicionais, vale também chamar a atenção para associações profissionais, com apenas 9,4\% de frequência.

Esses dados sugerem que encontramos em Maringá uma tendência de declínio da participação em modalidades dessa natureza, mais tradicionais, como os partidos e os sindicatos, o que está em consonância com o que vem sendo diagnosticado, de forma geral, para outras realidades (Ribeiro; Ayres, 2011). No que diz respeito ao panorama geral, os dados indicam um grau de participação mediano de pequena parcela da população maringaense em associações, com exceção dos grupos religiosos que, como já foi mencionado, contam com grande presença.

Ao observar as respostas fornecidas, merece mais uma vez destaque o fato de o associativismo de cunho religioso ser superior a 75\% para todos os grupos etários, unificando um comportamento. Quando a participação em associativismo de tipo religioso é confrontada com outras modalidades, ficam evidentes o que classificamos de posturas mais conservadoras dos idosos: enquanto $85,7 \%$ deles participam do associativismo religioso, nenhum participa de partidos políticos. Em contrapartida, os jovens, mesmo com alta frequência no associativismo religioso $(76,3 \%)$, indicam um tipo de "reserva latente" (Mannheim, 1961, p. 42) para as atitudes menos conservadorasquando os dados mostram sua participação em organizações de mulheres $(3,5 \%)$ e grupos LGBT $(3,6 \%)$.

Esses dados não nos permitem atestar, entretanto, diferenças significativas entre os grupos etários no que se refere à intensidade dos vínculos ou de participação em associações. O resultado do teste gam$m a($ sig $=, 805)$ nos diz que a quantidade de vínculos mantidos pelos indivíduos não se relaciona com os grupos etários.

Aplicamos também um modelo de regressão no qual os diferentes grupos etários foram decompostos em variáveis binárias, tomadas como preditoras do envolvimento associativo com as variáveis de controle "sexo" e "escolaridade". O resultado também indicou que não há diferenças entre o perfil de adultos diante de jovens e idosos no que diz respeito à intensidade de vínculos associativos. Cumpre notar que esse dado confronta um dos argumentos presentes na literatura sobre o comportamento político, que é o de que podemos encontrar níveis mais elevados de participação entre aqueles que, entre outros atributos, pertencem à faixa etária intermediária (Ribeiro; Ayres, 2011; Okado, 2013).

Ainda que o baixo envolvimento associativo da amostra de Maringá não permita identificar a associação estatística entre as variáveis, é possível apontar, como já anunciamos antes, algumas diferenças 
em termos relacionais. Notamos na Tabela 2 que o grupo entre 30-59 anos mantém maior envolvimento com associações do mundo do trabalho do que os demais; os idosos participam mais de organizações comunitárias; os jovens participam mais de organizações esportivas e recreativas e, ainda, são os únicos a participar de grupos LGBT.

Assim, temos que os grupos etários não se diferenciam no que diz respeito ao volume de vínculos associativos, mas apresentam algumas afinidades com determinados tipos de associação. Abstraindo a expressiva vinculação ao associativismo religioso presente para todos os grupos, é de se considerar que a participação em organizações de mulheres e em grupos LGBT produz uma distinção política importante para os jovens. Mais uma vez chamamos a atenção para a expressiva "não participação" dos dois grupos que estão em posição polares, jovens e idosos, em partidos políticos: apenas 1,8\% dos jovens participam e nenhum dos entrevistados entre os idosos disseram pertencer a essa modalidade associativa.

Ainda sobre essa instituição, a Tabela 3 a seguir mostra uma desconsideração geral da população de Maringá em relação ao partido ao qual pertence o candidato, no momento de suas escolhas eleitorais. Uma postura mais desconfiada em relação aos partidos políticos foi tomada pelos idosos no que se refere ao que deve ser considerado importante na hora de votar: apenas $11,3 \%$ dos que integram o grupo daqueles que têm 60 ou mais anos de idade disseram que o partido político ou a coligação são informações importantes na hora de decidir o voto. Já 21,8\% dos jovens disseram valorizar essa informação na hora de votar. Contudo, é importante considerar a proximidade da postura de jovens e idosos quando o assunto é a relevância por eles atribuída à pessoa do candidato. Expressivos 74,6\% de jovens e 82,9\% de idosos consideram que o candidato é o que deve definir, em última, instância, a escolha do voto.

Tabela 3 - Definição do voto por grupos etários

\begin{tabular}{|l|c|c|c|}
\hline \multirow{2}{*}{$\begin{array}{l}\text { O que é mais } \\
\text { importante na hora } \\
\text { de votar }\end{array}$} & \multicolumn{3}{|c|}{ Grupos Etários \% } \\
\cline { 2 - 4 } & 3,29 & $30-59$ & $60+$ \\
\hline $\begin{array}{l}\text { Não respondeu/não } \\
\text { sabe }\end{array}$ & 21,8 & 20,1 & 5,8 \\
\hline $\begin{array}{l}\text { O partido ou } \\
\text { coligação que } \\
\text { pertence o candidato }\end{array}$ & 74,6 & 76,1 & 82,9 \\
\hline A pessoa do candidato & 100,0 & 100,0 & 100,0 \\
\hline Total & & & \\
\hline
\end{tabular}

$\mathrm{N}=309$

Fonte: Projeto Cultura, Política e Gênero.
A Tabela 4 apresenta as respostas fornecidas à pergunta sobre o quanto os respondentes consideram-se conhecedores dos acontecimentos políticos do país.

Tabela 4 - Opinião dos respondentes sobre o conhecimento que possui sobre os acontecimentos políticos por Grupos Etários

\begin{tabular}{|l|c|c|c|}
\hline \multirow{2}{*}{$\begin{array}{l}\text { Conhecimento sobre } \\
\text { acontecimentos } \\
\text { políticos }\end{array}$} & \multicolumn{3}{|c|}{ Grupos Etários \% } \\
\cline { 2 - 4 } & $16-29$ & $30-59$ & $60+$ \\
\hline $\begin{array}{l}\text { Não sabe quase nada } \\
\text { ou conhece pouco }\end{array}$ & 79,0 & 63,5 & 77,1 \\
\hline $\begin{array}{l}\text { Conhece ou conhece } \\
\text { muito }\end{array}$ & 21,0 & 36,5 & 36,5 \\
\hline Total & 100,0 & 100,0 & 100,0 \\
\hline
\end{tabular}

$\mathrm{N}=309$

Fonte: Projeto Cultura, Política e Gênero.

Mais de 70\% dos que integram os grupos de jovens e idosos afirmam não saber quase nada ou conhecem pouco dos acontecimentos políticos do país. Entre aqueles que estão na faixa etária de 30-59 anos, o desconhecimento desses assuntos cai para 63,5\%. Conforme mostra a Tabela 5, movimento semelhante se reproduziu para a pergunta que interrogou o interesse dos entrevistados por política.

Tabela 5 - Opinião sobre interesse por política

\begin{tabular}{l|c|c|c|}
\hline \multirow{2}{*}{$\begin{array}{l}\text { Interesse por } \\
\text { política }\end{array}$} & \multicolumn{3}{|c|}{ Grupos Etários \% } \\
\cline { 2 - 4 } $\begin{array}{l}\text { Não sou interessado } \\
\text { ou não muito } \\
\text { interessado }\end{array}$ & 53,5 & $30-59$ & $60+$ \\
\hline $\begin{array}{l}\text { Um pouco ou } \\
\text { muito interessado }\end{array}$ & 46,5 & 58,5 & 48,6 \\
\hline Total & 100,0 & 100,0 & 100,0 \\
\hline
\end{tabular}
$\begin{aligned} & \text { N=309 } \\
& \text { Fonte: Projeto Cultura, Política e Gênero. }\end{aligned}$

Apenas para os que integram o grupo etário de 30-59 anos o percentual dos que dizem ter algum interesse pela política supera os $50 \%$. Merece destaque o fato de os jovens manifestarem que se interessam menos ainda por política do que os idosos: $53,5 \%$ de jovens, contra $51,4 \%$ de idosos.

Quisemos saber, então, a relação entre essas duas variáveis. O teste de significância para "interesse político" e "conhecimento sobre política" resultou estatisticamente forte (Gamma de ,684 com sig= ,000), indicando que as respostas positivas para ambas as variáveis estão associadas. Ou seja, o respondente que se considera conhecedor dos assuntos políticos tende 
a ser também interessado por política. A partir dessa constatação, quisemos saber se essa associação varia entre os grupos etários. Para tanto, com a aplicação de um modelo de regressãoem que os grupos etários foram tomados como preditores (variáveis binárias), tendo como referência os jovens, e com as variáveis de controle "sexo" e "escolaridade", constatamos que, primeiro, nesse grupo há uma menor probabilidade de encontrarmos as variáveis "interesse por política" e "conhecimento de política" associadas. Segundo, os idosos e os adultos não se diferenciam no que diz respeito à presença dessa associação de variáveis. $\mathrm{Ou}$ seja, tanto um como o outro grupo consideram-se interessados e conhecedores de política na mesma intensidade.

Esses dados diferem do que Okado (2013) encontrou para a realidade nacional. Embora o autor tenha trabalhado com faixas etárias não exatamente coincidentes com as que estamos tratando aqui, sua análise concluiu que não existem diferenças significativas nos dados que permitam atestar que os mais jovens nutram menor interesse por política. No que diz respeito aos nossos dados, é relevante chamar a atenção também para o fato de idosos e adultos não se diferenciarem no que diz respeito ao interesse por política e avaliação sobre o autoconhecimento de assuntos políticos.

Passemos agora para os dados que mostram a disposição da população entrevistada para participar de atividades de perfil mais contestatório. Na lista de atividades constavam abaixo-assinados, boicotes, manifestações, passeatas e greves. Para cada uma dessas modalidades, ao somarmos as alternativas escolhidas "poderia fazer" e "já fiz", temos um índice que mostra a disposição da população e dos grupos etários para participar desse tipo de atividade. Os resultados para esse índice são apresentados pela Tabela 6, a qual destina a última coluna para os percentuais correspondentes ao universo total de nossa amostra e as demais, aos diferentes grupos etários.

Considerando primeiro os percentuais para o total de nossa amostra, percebemos que $34,2 \%$ dos entrevistados apresentam disposição para participar das cinco modalidades de contestação; $21,7 \%$, de quatro; 14,8\% de três; e assim por diante. Entretanto, é importante mencionar que se fôssemos considerar apenas a frequência correspondente à alternativa "já fiz", ou seja, se fôssemos considerar apenas os indivíduos que disseram já ter participado de todas as atividades listadas, teríamos que 33\% nunca participaram e 35\% participaram de apenas uma. Somente $2 \%$ disseram ter participado de todas as atividades listadas.
Tabela 6 - Índice de disposição para participação em atividades contestatória ${ }^{\star}$

\begin{tabular}{|c|c|c|c|c|}
\hline \multirow{2}{*}{$\begin{array}{c}\text { Índice de } \\
\text { disposição }\end{array}$} & \multicolumn{3}{|c|}{ Grupos etários \% } & $\begin{array}{c}\text { Total } \\
\text { entre os } \\
\text { entrevistados } \\
\%\end{array}$ \\
\cline { 2 - 4 } & $16-29$ & $30-59$ & $60+$ & 3,9 \\
\hline, 00 &, 9 & 3,2 & 17,6 & $3,9,1$ \\
\hline 1,00 & 9,7 & 19,7 & 38,2 & 18,1 \\
\hline 2,00 & 4,4 & 10,2 & 2,9 & 7,2 \\
\hline 3,00 & 15,9 & 15,3 & 8,8 & 14,8 \\
\hline 4,00 & 24,8 & 19,7 & 20,6 & 21,7 \\
\hline 5,00 & 44,2 & 31,8 & 11,8 & 34,2 \\
\hline Total & 100,0 & 100,0 & 100,0 & 100,0 \\
\hline
\end{tabular}

$\mathrm{N}=309$

* O resultado desse índice corresponde à somatória das respostas que atestaram a disposição de participar das modalidades de contestação relacionadas na Tabela 7 .

Fonte: Projeto Cultura, Política e Gênero.

Agora, considerando os grupos etários, o teste de significância deu um retorno estatisticamente aceitável e negativo (Gamma de,$- 371 \mathrm{com}$ sig $=, 000$ ), indicando que quanto menor a idade, maior é a chance, nessa população, de envolvimento em atividades mais contestatórias, o que confirma, nesse caso, a suposição de Mannheim (1961, p. 40-41) de que se a juventude não é "progressista por índole", ela é um "agente revitalizador da vida social".

Ao especificar as diferentes modalidades de atividade e suas respectivas alternativas, a próxima tabela detalha os dados encontrados para os grupos etários em relação às atividades contestatórias, lembrando que os entrevistados podiam ainda optar pela alternativa "não respondeu".

Como podemos observar nessa tabela, principalmente ao considerarmos as frequências obtidas pela opção "não faria nunca", as distâncias entre jovens e idosos são significativas, evidenciando uma característica da juventude: maior disposição para contestação. A dissonância fica mais evidente quando jovens e idosos passam a se pronunciar sobre se teriam ou não disposição em participar de passeatas (lembramos que o survey foi aplicado bem antes das manifestações de rua do mês de junho de 2013). Para a questão que indagava sobre a disposição em participar das passeatas de rua, 14,9\% dos jovens responderam que nunca o fariam e significativos $60 \%$ idosos disseram que nunca fariam uma passeata. Assim, a diferença entre jovens e idosos começa a ficar significativa quando observamos a probabilidade de participação em algumas modalidades de tipo mais contestatória, atestando a associação antes mencionada entre o grupo dos 
jovens e esse tipo de participação. Ou seja, naquele campo de disputas que pode pender tanto para posturas mais participativas ou menos participativas, que seria uma característica, segundo Mannheim (1961), da juventude: $56 \%$ dos jovens disseram que poderiam fazer passeatas e apenas $28,6 \%$ dos idosos aventaram essa possibilidade.

Tabela 7 - Disposição para ativismo contestatório

\begin{tabular}{|c|c|c|c|c|}
\hline \multirow{2}{*}{$\begin{array}{l}\text { Modalidade } \\
\text { de ativismo } \\
\text { contestatório }\end{array}$} & \multirow{2}{*}{ Disposição } & \multicolumn{3}{|c|}{ Grupos Etários \% } \\
\hline & & $16-29$ & $30-59$ & $60+$ \\
\hline \multirow{3}{*}{$\begin{array}{l}\text { Abaixo- } \\
\text { assinados }\end{array}$} & Não faria nunca & 4,4 & 4,4 & 22,9 \\
\hline & Poderia fazer & 29,8 & 31,4 & 42,9 \\
\hline & Já fiz & 65,8 & 63,5 & 34,3 \\
\hline \multirow{3}{*}{ Boicotes } & Não faria nunca & 44,7 & 56,6 & 77,1 \\
\hline & Poderia fazer & 43,0 & 34,0 & 14,3 \\
\hline & Já fiz & 11,4 & 8,2 & 5,7 \\
\hline \multirow{3}{*}{ Manifestações } & Não faria nunca & 21 & 35,8 & 57,1 \\
\hline & Poderia fazer & 59,6 & 45,9 & 28,6 \\
\hline & Já fiz & 19,3 & 17,6 & 14,3 \\
\hline \multirow{3}{*}{ Passeatas } & Não faria nunca & 14,9 & 32,7 & 60 \\
\hline & Poderia fazer & 56,0 & 47,8 & 28,6 \\
\hline & Já fiz & 28,9 & 18,9 & 11,4 \\
\hline \multirow{3}{*}{ Greves } & Não faria nunca & 27,2 & 44 & 71,4 \\
\hline & Poderia fazer & 64 & 34,6 & 14,3 \\
\hline & Já fiz & 8,8 & 20,8 & 14,3 \\
\hline
\end{tabular}

$\mathrm{N}=309$

Fonte: Projeto Cultura, Política e Gênero.

\section{Considerações finais}

Os dados referentes à população de Maringá mostram um alto índice de participação em associações religiosas para todos os grupos etários e permitem afirmar que, entre esses, não há diferenças significativas em termos de intensidade de envolvimento em associações, apresentando, assim, um contraponto a argumentos que consideram determinadas faixas etárias mais propensas ao engajamento associativo. De outro lado, nossos dados sugerem, para essa população, a tendência detectada para outras escalas e realidades de declínio da participação em modalidades mais tradicionais, como os partidos e os sindicatos. Para a população que investigamos aqui, os jovens são mais propensos à participação em modalidades contestatórias do que os outros grupos etários. Entretanto, diante destes, os jovens se sentem menos conhecedores da política e menos interessados nos assuntos que lhe dizem respeito.
Desde que Mannheim falou, em 1928, sobre a possibilidade de existir um "vínculo geracional", que é fruto de experiências vividas na contemporaneidade e que permitem a diferentes grupos etários vivenciar tempos interiores diferentes em um mesmo período cronológico, pesquisadores tentam apreender qualitativamente o sentido dessa observação (Weller, 2010). Os estudos sobre geração, juventude e agora sobre envelhecimento têm confirmado uma indicação de Mannheim (1961), o que justifica inclusive o uso de suas reflexões na atualidade: há uma espécie de não contemporaneidade dos contemporâneos. Ou seja, o fato de diferentes grupos geracionais, como jovens e idosos, dividirem um mesmo contexto histórico, político e social não implica em uma vivência partilhada de valores e comportamentos.

No caso por nós analisado, é marcante a insistência de traços semelhantes para os diferentes grupos geracionais que compartilharam uma mesma vivência histórica, pois jovens e idosos maringaenses evidenciam características comuns, que conjugam uma valorização do associativismo de cunho religioso, distanciamento de organizações tradicionais, como os partidos políticos, além de não apresentarem diferenças em termos de volume no engajamento associativo. Contudo, como indicou Mannheim, pensando outro contexto histórico (1961), os dois grupos geracionais se diferenciam em alguns importantes aspectos. Os jovens demonstram um comportamento mais aberto em relação às novas formas de participação no mundo da política, como por exemplo, as passeatas, e são também menos resistentes às greves. $\mathrm{O}$ comportamento político desses dois grupos geracionais aponta a necessidade de continuarmos a discutir o recorte geracional e a vitalidade de seu uso para refletirmos sobre processos de transmissão de bens culturais e da cultura política.

As questões que ficam para respondermos com outras investigações são: 1) nessa fase de nossa transição demográfica, em que os idosos crescem muito mais do que os jovens, como ficarão as mudanças e as rupturas nos padrões de transmissão dos bens culturais e da cultua política, 2) em uma sociedade que apenas recentemente reconheceu os direitos da pessoa idosa e continua os vendo como um "problema social", como garantir que o resgate da memória e da recordação social desse grupo se viabilize e 3) a diminuição do número de jovens e seu reconhecimento tardio como sujeitos de direito terá qual importância no debate sobre associativismo político, atitudes contestatórias e grau de conservadorismo ou progressismo da sociedade moderna. 


\title{
Referências
}

BARROS, Myriam M. L. A velhice na pesquisa socioantropológica brasileira. In: GOLDENBERG, Mirian (Org.). Corpo, envelhecimento e felicidade. Rio de Janeiro: Civilização Brasileira, 2011. p. 45-64.

BEAUVOIR, Simone. A velhice. Rio de Janeiro: Nova Fronteira, 1990.

BOSI, Ecléa. Memória e sociedade: lembranças de velhos. São Paulo: Companhia das Letras, 2010.

BOURDIEU, Pierre. A juventude é apenas uma palavra. In: ______. Questões de sociologia. Rio de Janeiro: Marco Zero, 1983. p. 112-121.

BRITO, Fausto. Transição demográfica e desigualdades sociais no Brasil. Revista Brasileira de Estudos Populacionais, v. 25, n. 1, p. 5-26, São Paulo, jan./jun. 2008.

GOLDMAN, Márcio. Como funciona a democracia: uma teoria etnográfica da política. Rio de Janeiro: Sete Letras, 2006.

GOLDMAN, Márcio; SILVA, A. C. Por que se perde uma eleição? In: GOLDMAN, Márcio (Org.). Alguma antropologia. Rio de Janeiro: Relume Dumará, 1999. p. 145-166.

HEREDIA, Beatriz; PALMEIRA, Moacir. O voto como adesão: teoria e cultura. Revista do Mestrado em Ciências Sociais, UFJF, v. 1, n. 1, p. 35-58, 2006.

KUSCHNIR, Karina. O cotidiano da política. Rio de Janeiro: Jorge Zahar, 2000.

MANNHEIM, Karl. Diagnóstico de nosso tempo. Rio de Janeiro: Jorge Zahar, 1961. p. 36-61.

MILBRATH, L. W.; GOEL M. L. Political participation: howandwhy do people getinvolved in politics? Chicago: Rand McNally College Publishing, 1977.

OKADO, Lucas. Juventude e participação política no Brasil: efeitos de ciclos de vida ou geração? Dissertação (Mestrado em Ciências Sociais) - Universidade Estadual de Maringá, Maringá, SP, 2013.

RIBEIRO, Ednaldo A.; AYRES, Carla S. Democracia, participação e mudança geracional no Brasil. Século XXI, UFSM, Santa Maria, RS, v. 1, n. 2, p. 62-78, jul./dez. 2011.

PALMEIRA, Moacir. Eleição municipal, política e cidadania. In: PALMEIRA, Moacir; BARREIRA, César (Orgs.). Política no Brasil. Rio de Janeiro: Relume Dumará, 2006. p. 137-150.

Política e tempo: nota exploratória. In: PEIRANO, Mariza (Org.). O dito e o feito: ensaios de antropologia dos rituais. Rio de Janeiro: Relume Dumará, 2002. p. 171-177.

SIMÕES, Júlio A. A maior categoria do país: o aposentado como ator político. In: BARROS, Myriam M. L. (Org.). Velhice ou terceira idade? Rio de Janeiro: Fundação Getúlio Vargas, 2006. p. 13-33.

STUCCHI, Débora. O curso da vida no contexto da lógica empresarial: juventude, maturidade e produtividade na definição da pré-aposentadoria. In: BARROS, Myriam M. L. (Org.). Velhice ou terceira idade? Rio de Janeiro: Fundação Getúlio Vargas, 2006. p. 35-46.

VASCONCELOS, Ana Maria N.; GOMES, Marília M. Transição demográfica: a experiência brasileira. Epidemiologia e Serviços de Saúde. Brasília, v. 21, n. 4, p. 539-548, out./dez. 2012.

WELLER, Wivian. A atualidade do conceito de gerações de Karl Mannheim. Revista Sociedade e Estado, v. 25, n. 2, p. 205-224, maio/ago. 2010.

\section{The youth considered from the point of view of the process of becoming old: demography and political behavior of the generational groups}

\begin{abstract}
The political participation as far as generational samples are concerned has provided new and disturbed questions to the social sciences. This article analyzes the political behavior of young and elderly people, who live in the city of Maringá, North of Paraná State (Brazil). The analysis is based on data provided by a survey applied to a sample of the city population during the year of 2011 . This paper is structured into three sections: in the first, young and old people are social constructed categories, since youngsters are considered due to the huge growth of the elderly population; in the second section, the presence of the young and the elderly in Maringá is calculated; in the third, the political behavior of young and old people is discussed.
\end{abstract}

Key words: youth, aging, political behavior, demography, generational groups. 


\section{El joven pensado a partir del envejecimiento: la demografía y el comportamiento político de los grupos generacionales}

\section{Resumen}

La participación política considerada desde recortes generacionales ha planteado a las ciencias sociales, nuevas e inquietantes preguntas. En este trabajo se analiza el comportamiento político de los jóvenes y de los ancianos que viven en la ciudad de Maringá, en el norte de Paraná, a partir de datos proporcionados por una encuesta aplicada a una muestra de la población de la ciudad durante el año 2011. Además de la introducción y la conclusión, este artículo está organizado en tres partes: en primer lugar, se discute cómo la juventud y la vejez son categorías que se construyen socialmente y cómo, hoy en día, los jóvenes están pensados en función del enorme crecimiento de la población de edad avanzada; en segundo lugar, dimensionamos la presencia de los jóvenes y las personas mayores en Maringá y, en tercer lugar presentamos y discutimos el comportamiento político de los jóvenes y las personas mayores en Maringá.

Palabras clave: jóvenes, envejecimiento, conducta política, demografía de grupos generacionales.

Data de recebimento do artigo: 9/12/2013

Data de aprovação do artigo: 6/8/2014 